\title{
Technical Efficiency Of Social Foundations In A Multidimensional Context
}

\author{
Imelda S. Dorado, University of Santo Tomas, Philippines
}

Emilyn Cabanda, Regent University, USA

\begin{abstract}
The paper is the first attempt at examining the technical efficiency and benchmarking the performance of 15 social foundations in the Philippines for the period 2000-2005 using the data envelopment analysis (DEA) model. The $65.55 \%$ of social foundations are operating at increased returns to scale, $4.45 \%$ at decreased returns to scale and $30 \%$ at constant returns to scale. Forty percent of firms are efficiently utilizing their expenses and the majority shows resource excesses (capital and labor). All firms show output deterioration for donations and total awards to beneficiaries. With the aid of the DEA tool, measurement of the efficiency of social foundations has been verified and proven as manageable and quantifiable from a multidimensional assessment. Results reveal the importance of technical efficiency assessment for the non-profit sector.
\end{abstract}

Keywords: data envelopment analysis, non-profit performance, social foundation, technical efficiency

\section{INTRODUCTION}

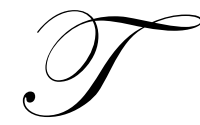

he performance of an organization/firm is usually evaluated based on profit maximization. There are many indicators that can be identified in relation to the performance of the firm in the economy, such as the return on capital, earnings per share, investment profile capital base, profitability, and market share. The profitability of the firm is oftentimes the best indicator for analysts to measure business performance in the profit sector. When the indicators of performance are multidimensional and profit is not the lone measurement, as in the case of non-profit sector, scholars and practitioners have to find an appropriate tool to measure performance, thus making it a problematic issue. What suitable assessment tool for the non-profit sector remains to be an unanswered issue in the field of performance measurement? In the non-profit sector, such as education and social foundations, as in the case of this paper, there is a need to identify other important non-financial indicators, aside from profit, in measuring performance and obtaining their organizational service goals.

Existing literature is abounding with studies on efficiency measure using data envelopment analysis (DEA) in analyzing the university's efficiency. Abbot and Doucouliagos (2003) provides critical information about the performance of various units that make up the universities and enable decision-making toward improvement in terms of efficiency and quality of the processes. Empirical analysis of the performance of universities typically takes the form of estimating cost functions with the focus on economies of size and scope or on the analysis of efficiency using DEA. Some studies that dealt with the DEA in measuring non-profit organizations worldwide are that of Castelli, Pesenti and Ukovich (2003), Taylor and Harris (2004), Thompson, Dharmapala and Thrall (1996), Joumady and Ris (2005), Athanassopoulos and Shale (1997), Robst (2001), and Ng and Li (2000). In the health industry, a few studies dealt with benchmarking as an improvement tool in health services based on DEA, ratio, and regression analysis (Dacosta-Claro and Lapierre, (2003), Nyhan and Cruise (2000), Harrison and Sexton (2006) and Biorn et al. (2003)).

Studies of efficiency performance in the education sector were also conducted by the following scholars: Castano and Cabanda (2007), Martin (2006), and Bougnol and Dula (2006). Nunamaker (1985) examined the potential effects of variable set expansion (either through disaggregation of existing variables or addition of new factors) and data upon the efficiency scores generated using the DEA model as applied to the non-profit sector. 
Ahn, Charnes and Cooper (1988) commented that Nunamaker's evaluation of DEA was inadequate and perhaps uneven-handed in that there was no discussion on some of the virtues (for example, dual variables) and extensions of DEA. Nunamaker (1988), in response to Ahn et al's criticism, stated that most non-profit organizations rely upon multiple surrogate measures in assessing organizational efficiency. Certain DMUs in these non-profit organizations would be rated efficient and thus rewarded somehow, even though the efficient rating results predominately from superior achievement on a variable that has a lower construct validity.

These existing studies, however, were focused on controllable variables in measuring efficiency performance, and they have a limited coverage on non-controllable variables. The apparent difference of this current research is the emphasis put on both controllable and non-controllable variables as indicators of performance and the use of an input-orientated slack-based DEA model that has never been attempted in the previous non-profit studies.

The purpose of this paper is to assess the relative technical or managerial efficiency of 15 Philippine social foundations for the period of 2000-2005 from a multidimensional context. Specifically, the paper attempts to 1) measure the technical efficiency of the Philippine social foundations, using the data envelopment analysis model, 2) determine accurate input excess and output deterioration (if there is any) for each firm and the needed percentage for improvement, and (3) identify which social foundation could serve as a benchmark peer for efficient performance. Results reveal the importance of technical efficiency assessment for the non-profit sector, which is a sector that always faces a performance constraint due to limited funds and difficulty in accessing funding for their services. Another significant contribution of the paper is the cost minimization strategy for the non-profit sector to remain viable and effective in their organizational service goals.

The remainder of the paper is structured as follows. Section 2 is a brief overview of the non-profit organization in the Philippines. Section 3 discusses methodology of data envelopment analysis for a multidimensional measurement of performance. Section 4 describes data sample and input/output variables for the model. Efficiency findings are assessed and analyzed in Section 5 and the final section concludes the paper.

\section{NON-PROFIT ORGANIZATIONS IN THE PHILIPPINES}

In the Philippines, there are social, cultural, religious, and non-profit organizations outside the government but operating within the framework of the law. These are referred to as non-government organizations (NGOs). These NGOs, which are organized for social action, community development, livelihood improvement and other purposes, are only a segment of a wider term "civil society," which currently refers to a politically conscious sector of society but not part of the military nor the insurgents. The Securities and Exchange Commission (SEC) estimates that there are nearly 60,000 non-stock, non-profit organizations in the country. In addition, there are thousands more of such groups unaccounted for, because they never registered with any government agency. However, the above population includes private schools and hospitals, professional associations, and other private non-profit institutions that are not usually encompassed by the term NGOs. At present, NGOs play a vital role in the socio-economic development of a country, especially those belonging to the developing countries like the Philippines. They provide support to the government in giving assistance to its constituents in various aspects such as scholarship, livelihood training, uplifting the living conditions, finances, medical services and the like.

Due to the benefits that the government and the people receive from NGOs, it is important that these NGOs observe good governance to ensure their continued relevance to society. NGOs, by their nature, largely depends on the benevolence of their benefactors whether individuals or corporations. Even free contributions or even non-profit organizations need to be efficiently managed to maximize their impact with minimum input resources. This is especially true for NGOs because almost all inputs, including employees or administrators are scarce, because NGO's work is largely voluntary in nature. However, there is a growing concern among people that due to initiatives of NGOs, the government has become complacent in its role and has relied on NGOs in the delivery of services and products that the government should have been doing in the first place. 


\section{METHODOLOGY: DATA ENVELOPMENT ANALYSIS (DEA)}

DEA as originally proposed by Charnes et al. (1978), is a non-parametric frontier estimation methodology for evaluating relative efficiencies and performance of a collection of related comparable entities called decisionmaking units (DMUs) in transforming inputs into outputs. DEA's domain can be any group of many entities characterized by the same set of multiple attributes.

DEA constructs a non-parametric envelopment frontier over the data points that all the observed points lay on, or below the production frontier when input-oriented measure is adopted. Assuming constant returns to scale, the following duality in the linear programming problem need to be solved (Coelli, 2005):

$$
\begin{aligned}
& \min _{\theta, \lambda} \theta, \\
& \text { st }-y_{i+} Y \lambda \geq 0, \\
& \theta x_{i}-X \lambda \geq 0, \\
& \lambda \geq 0,
\end{aligned}
$$

where $\theta$ is a scalar and $\lambda$ is a $\mathrm{Nx} 1$ vector of constants. This envelopment form involves fewer constraints than the multiplier form $(\mathrm{K}+\mathrm{M}<\mathrm{N}+1)$, and hence is generally the preferred form to solve. The value of $\theta$ obtained will be the efficiency score for the i-th DMU. This will satisfy $\theta \leq 1$, with a value of 1 indicating a point on the frontier and hence a technically efficient DMU, according to Farrell (1957) (Coelli, 2005, p. 163). It is noted that the linear programming problem must be solved $\mathrm{N}$ times, once each DMU in the sample. A value $\theta$ is then obtained for each DMU. The Slack-based DEA model was used to derive all constant returns to scale (CRS) and variable returns to scale (VRS) slack results under the input-orientation measure, using the DEA Frontier software (Cook and Zhu, 2005). Koopmans in 1951 provides a more strict definition of technical efficiency which is equivalent to stating that a firm is only technically efficient if it operates on the frontier, and that all associated slacks are zero (Coelli, 2005, p.164). Slack is an important feature of DEA, which reflects either surpluses (inputs) or shortages/deterioration (outputs) in service production. We analyze here whether input and output slacks have led to inefficiencies of social foundations.

This paper employs input-oriented measure. Input-oriented is a measure of performance used when the input can be reduced without changing the output. This is particularly appropriate for a non-profit sector (i.e., social foundations) in which the goal is cost saving to obtain desirable goals (service) rather than profit maximization. In this paper, we also attempt to analyze whether the firms are operating at economies of scale. If a proportionate increase in all inputs results in less than proportionate increase in output, this exhibits decreasing returns to scale (DRS). When a proportionate increase inputs leads to a more than proportionate increase in output, this signifies increasing returns to scale (IRS) (Coelli et al., 2005). Combining the two extremes (IRS and DRS) would necessitate variable returns to scale (VRS). Thus, VRS is known as the ability of the firm to catch up, given limitations like imperfect competition, constraints on finances, etc. that may cause the firm not to be operating at optimal scale. Another variant of economies of scale is constant returns to scale (CRS). This signifies that the firm is able to scale the inputs and outputs linearly without increasing or decreasing efficiency (Ramanathan, 2003).

\section{DATA SAMPLES AND VARIABLES}

Table 1 shows the 15 social foundations listed as a member of League of Corporate Foundations due to the availability of the data throughout the period of analysis.

This paper uses three outputs and four inputs that are considered relevant and important in the performance of social foundations. Outputs include (1) donations received from the benefactors; (2) Interest Income; and (3) Grants/Awards to Beneficiaries. Inputs included are (1) Administrative and General Operating Expenses (2) Fixed Asset, (3) the number of employees (full-time equivalent) and (4) Age (years of existence). By definition, the donations received are those total donations given by the benefactors to the foundations. Donations refer to external funds given by other organization or businesses and considered as output in line with the foundation's purpose to raise funds for their programs. Interest incomes are those incomes that earned from investment, savings account and similar fixed income investment. Grants/awards are those projects given by the foundation to the beneficiaries of 
their projects. The administrative and operating expenses are those expenses incurred by an organization. Fixed assets include properties, plants, and equipments. The number of employees is a productive workforce or the number of full-time employees of the organization. The age of the foundation shows how long the foundation has been in operation. This input is the only non-controllable variable in our model while other variables are taken to be controllable (within management discretion).

Table 1: Philippine Social Foundations included in the Research Samples

\begin{tabular}{clc}
\hline Year Est. & Foundations & Denoted by \\
\hline 1968 & A. Soriano Foundation & ASF \\
1970 & AY Foundation & AYF \\
1961 & Ayala Foundation* & AFI \\
1991 & Bato Balani Foundation, Inc. & BBFI \\
1986 & Coca-Cola Foundation Philippines,Inc. & CCFPI \\
1990 & E.Zobel Foundation & EZF \\
1979 & Metrobank Foundation & MBF \\
1992 & Philippine Airlines Foundation & PALF \\
1970 & Philippine Business for Social Progress & PBSP \\
1994 & PLDT Foundation & PLDTF \\
1982 & Pilipinas Shell Foundation,Inc. & PSFI \\
1991 & RFM Foundation & RFMF \\
1983 & SM Foundations & SMF \\
1997 & Splash Foundation & SF \\
1991 & Tan Yan Kee Foundation & TYKF \\
\hline
\end{tabular}

* Founded as Filipinas Foundation in 1961; adopted the name Ayala Foundation in 1991.

These output and input measures were calculated for the test periods of 2000 to 2005 for 15 social foundations in the Philippines or a total of 90 pooled data. The data for analysis were obtained from audited and published annual reports that are available from the Philippine Securities and Exchange Commission.

\section{EMPIRICAL FINDINGS}

With the use of "input-oriented DEA" (I/O DEA) model, the technical efficiency of the 15 social foundations in the Philippines was calculated for every year of analysis. New findings reported in Tables 2 and 3 from 2000 - 2005 show that the technical efficiency (TE) of the firm in CRS and VRS has a variation. On average, Table 2 results show that $69 \%$ CRS means that social foundations have difficulty maintaining efficiency, given variations in administrative and general operating expenses, fixed assets, number of employee and age of the foundation on one hand and grants awarded to beneficiaries, donations and interest income on the other hand.

Table 2: Average Efficiency Performance per Social Foundation Constant Returns to Scale Technical Efficiency

\begin{tabular}{lcccccccc}
\multicolumn{1}{c}{ Firm } & $\mathbf{2 0 0 0}$ & $\mathbf{2 0 0 1}$ & $\mathbf{2 0 0 2}$ & $\mathbf{2 0 0 3}$ & $\mathbf{2 0 0 4}$ & $\mathbf{2 0 0 5}$ & Average & DEA Ranking \\
\hline ASF & 0.54255 & 0.65407 & 0.54275 & 0.70582 & 1.00000 & 1.00000 & 0.74087 & 9 \\
AYF & 0.71500 & 1.00000 & 0.68250 & 1.00000 & 0.97655 & 1.00000 & 0.89568 & 4 \\
AFI & 1.00000 & 0.98527 & 1.00000 & 0.88847 & 0.95724 & 1.00000 & 0.97183 & 1 \\
BBFI & 1.00000 & 0.91032 & 1.00000 & 0.87299 & 0.69527 & 1.00000 & 0.91310 & 3 \\
CCFPI & 1.00000 & 1.00000 & 0.94166 & 0.98908 & 0.63417 & 0.65788 & 0.87047 & 5 \\
EZF & 0.48736 & 0.16895 & 0.27039 & 0.16529 & 0.10825 & 0.25213 & 0.24206 & 14 \\
MBF & 0.86658 & 1.00000 & 0.76623 & 0.93875 & 0.79493 & 0.76708 & 0.85560 & 8 \\
PALF & 0.10456 & 0.24193 & 0.32284 & 0.49641 & 0.31710 & 0.49538 & 0.32970 & 13 \\
PBSP & 0.76183 & 0.87552 & 1.00000 & 1.00000 & 1.00000 & 1.00000 & 0.93956 & 2 \\
PLDTF & 0.57565 & 0.51371 & 0.17791 & 0.50880 & 0.49332 & 1.00000 & 0.54490 & 11 \\
PSFI & 0.82535 & 1.00000 & 0.66058 & 0.66242 & 1.00000 & 1.00000 & 0.85806 & 7 \\
RFMF & 0.18829 & 0.22844 & 0.23410 & 0.12210 & 0.36143 & 0.28382 & 0.23636 & 15 \\
SMF & 0.43157 & 0.39113 & 0.25661 & 0.37505 & 0.35700 & 0.43342 & 0.37413 & 12 \\
SF & 1.00000 & 0.81117 & 0.53524 & 0.67462 & 0.49555 & 0.57521 & 0.68197 & 10 \\
TYKF & 1.00000 & 1.00000 & 1.00000 & 0.30998 & 0.87589 & 1.00000 & 0.86431 & 6 \\
\hline Ave. & 0.69992 & 0.71870 & 0.62605 & 0.64732 & 0.67111 & 0.76433 & 0.68791 &
\end{tabular}


The $83 \%$ average under VRSTE (Table 3) indicates that social foundations are better characterized as comprising an organization, with a very pronounced variable return to scale than one with a constant return to scale. This VRSTE characteristic is important for two reasons. First, under VRSTE, there is an underlying assumption that allowance is made to isolate the managerial efficiencies. Second, since the foundations exhibit a VRSTE characteristic, then it is possible to identify and isolate managerial efficiencies. Tables 2 and 3 show that, on average under both assumptions, no firm has reached the frontier.

Table 3: Average Efficiency Performance per Social Foundation Variable Returns to Scale Technical Efficiency (VRSTE), 2000 - 2005

\begin{tabular}{|c|c|c|c|c|c|c|c|c|}
\hline Firm & 2000 & 2001 & 2002 & 2003 & 2004 & 2005 & Average & $\begin{array}{c}\text { DEA } \\
\text { Ranking }\end{array}$ \\
\hline ASF & 0.84200 & 0.88640 & 0.77596 & 0.85578 & 1.00000 & 1.00000 & 0.89336 & 6 \\
\hline AYF & 0.71994 & 1.00000 & 0.46440 & 1.00000 & 0.97715 & 1.00000 & 0.86025 & 11 \\
\hline AFI & 1.00000 & 1.00000 & 1.00000 & 0.88860 & 1.00000 & 1.00000 & 0.98143 & 2 \\
\hline BBFI & 1.00000 & 1.00000 & 1.00000 & 0.98211 & 1.00000 & 1.00000 & 0.99702 & 1 \\
\hline CCFPI & 1.00000 & 1.00000 & 0.95644 & 0.99443 & 0.63872 & 0.68488 & 0.87908 & 8 \\
\hline EZF & 0.67169 & 0.37072 & 0.34953 & 0.31260 & 0.29826 & 0.35304 & 0.39264 & 15 \\
\hline $\mathrm{MBF}$ & 0.87659 & 1.00000 & 0.77672 & 1.00000 & 0.79734 & 0.77086 & 0.87025 & 9 \\
\hline PALF & 1.00000 & 0.99250 & 1.00000 & 1.00000 & 0.91068 & 0.95689 & 0.97668 & 3 \\
\hline PBSP & 0.76292 & 0.87977 & 1.00000 & 1.00000 & 1.00000 & 1.00000 & 0.94045 & 4 \\
\hline PLDT & 1.00000 & 1.00000 & 1.00000 & 0.80407 & 0.78729 & 1.00000 & 0.93189 & 5 \\
\hline PSFI & 0.84034 & 1.00000 & 0.69011 & 0.69089 & 1.00000 & 1.00000 & 0.87022 & 10 \\
\hline RFMF & 0.78953 & 0.77935 & 0.81971 & 0.63571 & 0.63580 & 0.62997 & 0.71501 & 13 \\
\hline SMF & 0.62342 & 0.47998 & 0.34900 & 0.43500 & 0.39480 & 0.45335 & 0.45593 & 14 \\
\hline SF & 1.00000 & 0.95241 & 0.86348 & 0.76406 & 0.71752 & 0.63057 & 0.82134 & 12 \\
\hline TYKF & 1.00000 & 1.00000 & 1.00000 & 0.44285 & 0.90681 & 1.00000 & 0.89161 & 7 \\
\hline Ave. & 0.87510 & 0.88941 & 0.80302 & 0.78707 & 0.80429 & 0.83197 & 0.83181 & \\
\hline
\end{tabular}

Tables 4 and 5 report which among the social foundations are located on the efficiency frontier under CRS and VRS models. Table 4 displays the number of counts of a 100\% efficient firm, with a total count of 27 from the years 2000 to 2005 with the CRS specification, and a total count of 38 under VRS assumption as shown in Table 5.

Table 4: Technical Efficiency Scores with CRS Specification and Input-Orientation

\begin{tabular}{|c|c|c|c|c|c|c|c|c|}
\hline DMU & Firm & 2000 & 2001 & 2002 & 2003 & 2004 & 2005 & Count \\
\hline 1 & A. Soriano Foundation & & & & & $x$ & $x$ & 2 \\
\hline 2 & AY Foundation & & $x$ & & $x$ & & $x$ & 3 \\
\hline 3 & Ayala foundation & $x$ & & $x$ & & & $x$ & 3 \\
\hline 4 & Bato-Balani Foundation & $x$ & & $x$ & & & $x$ & 3 \\
\hline 5 & Coca-cola Foundation & $x$ & $x$ & & & & & 2 \\
\hline 6 & E. Zobel Foundation & & & & & & & \\
\hline 7 & Metrobank Foundation & & $x$ & & & & & 1 \\
\hline 8 & Philippine Airline Foundation & & & & & & & \\
\hline 9 & Phil. Business Social Progress & & & $x$ & $x$ & $x$ & $x$ & 4 \\
\hline 10 & Phil. Long Distance Foundation & & & & & & $x$ & 1 \\
\hline 11 & Pilipinas Shell Foundation & & $x$ & & & $x$ & $x$ & 3 \\
\hline 12 & RFM Foundation & & & & & & & \\
\hline 13 & SM Foundation & & & & & & & \\
\hline 14 & Splash Foundation & $x$ & & & & & & 1 \\
\hline 15 & Total & 5 & 5 & 4 & 2 & 3 & 8 & 27 \\
\hline
\end{tabular}

Note: The firms corresponding to the shaded region have not been efficient in any year in the sample period (2000-2005) compared to the other firms in the sample. X represents the efficiency in a given year. 
Table 5: Technical Efficiency Scores with VRS Specification and Input Orientation

\begin{tabular}{|c|c|c|c|c|c|c|c|c|}
\hline DMU & Firm & 2000 & 2001 & 2002 & 2003 & 2004 & 2005 & Count \\
\hline 1 & A. Soriano Foundation & & & & & $x$ & $x$ & 2 \\
\hline 2 & AY Foundation & & $x$ & & $x$ & & $x$ & 3 \\
\hline 3 & Ayala foundation & $x$ & $x$ & $x$ & & $x$ & $x$ & 5 \\
\hline 4 & Bato-Balani Foundation & $x$ & $x$ & $x$ & & $x$ & $x$ & 5 \\
\hline 5 & Coca-cola Foundation & $x$ & $x$ & & & & & 2 \\
\hline 6 & E. Zobel Foundation & & & & & & & \\
\hline 7 & Metrobank Foundation & & $x$ & & $x$ & & & 2 \\
\hline 8 & Philippine Airline Foundation & $x$ & & $x$ & $x$ & & & 3 \\
\hline 9 & Phil. Business Social Progress & & & $x$ & $x$ & $x$ & $x$ & 4 \\
\hline 10 & Phil. Long Distance Foundation & $x$ & $x$ & $x$ & & & $x$ & 4 \\
\hline 11 & Pilipinas Shell Foundation & & $x$ & & & $x$ & $x$ & 3 \\
\hline 12 & RFM Foundation & & & & & & & \\
\hline 13 & SM Foundation & & & & & & & \\
\hline 14 & Splash Foundation & $x$ & & & & & & 1 \\
\hline \multirow[t]{2}{*}{15} & Tan Yan Kee Foundation & $x$ & $x$ & $x$ & & & $x$ & 4 \\
\hline & Total & 7 & 8 & 6 & 4 & 5 & 8 & 38 \\
\hline
\end{tabular}

Note: The firms corresponding to the shaded regions have not been efficient in any year in the sample period (2000 - 2005) compared to the other firms in the sample. $\mathrm{X}$ represents the efficiency in a given year.

Tables 6 to 8 show the social foundations that rest on the efficiency frontier under the return to scale technical efficiency. Input-oriented measures of efficiency answers the question up to what extent the factor inputs can be proportionally reduced for a given level of outputs.

Table 6 shows a CRS efficiency performance for the period 2000 to 2005. The firms with $x$ marks are the most efficient firms and are considered operating at the most productive scale sizes.

Table 6: Number of firms with Input-Orientated CRS Efficiency

\begin{tabular}{|c|c|c|c|c|c|c|c|}
\hline Firm & No. & 2000 & 2001 & 2002 & 2003 & 2004 & 2005 \\
\hline ASF & 1 & & & & & $x$ & $x$ \\
\hline AYF & 2 & & $x$ & & $x$ & & $x$ \\
\hline AFI & 3 & $x$ & & $x$ & & & $x$ \\
\hline BBFI & 4 & $x$ & & $x$ & & & $x$ \\
\hline CCFPI & 5 & $x$ & $x$ & & & & \\
\hline EZF & 6 & & & & & & \\
\hline $\mathrm{MBF}$ & 7 & & $x$ & & & & \\
\hline PALF & 8 & & & & & & \\
\hline PBSP & 9 & & & $x$ & $x$ & $x$ & $x$ \\
\hline PLDTF & 10 & & & & & & $x$ \\
\hline PSFI & 11 & & $x$ & & & $x$ & $x$ \\
\hline RFMF & 12 & & & & & & \\
\hline SMF & 13 & & & & & & \\
\hline SF & 14 & $x$ & & & & & \\
\hline TYKF & 15 & $x$ & $x$ & $x$ & & & $x$ \\
\hline
\end{tabular}

Note: The firms with $\mathrm{x}$ mark represent the efficiency with Constant Returns to Scale (CRS) in a given year.

Entries on Table 7 indicate that firms are operating at lower scale sizes because they can achieve greater economies by increasing their volume of operation for the time period 2000-2005. In Table 8, there are only three firms that showed decreasing return to scale performance, which implies that these firms operate at higher scale sizes. They were AY Foundation in 2004, Ayala Foundation in 2001 and 2004, and the Metrobank Foundation in 2003. 
Table 7: Number of Firms with Input-Orientated IRS Efficiency

\begin{tabular}{|c|c|c|c|c|c|c|c|}
\hline Firm & No. & 2000 & 2001 & 2002 & 2003 & 2004 & 2005 \\
\hline ASF & 1 & $x$ & $x$ & $x$ & $x$ & & \\
\hline AYF & 2 & $x$ & & $x$ & & & \\
\hline AFI & 3 & & & & $x$ & & \\
\hline BBFI & 4 & & $x$ & & $x$ & $x$ & \\
\hline CCFPI & 5 & & & $x$ & $x$ & $x$ & $x$ \\
\hline $\mathrm{EZF}$ & 6 & $x$ & $x$ & $x$ & $x$ & $x$ & $x$ \\
\hline $\mathrm{MBF}$ & 7 & $x$ & & $x$ & & $x$ & $x$ \\
\hline PALF & 8 & $x$ & $x$ & $x$ & $x$ & $x$ & $x$ \\
\hline PBSP & 9 & $x$ & $x$ & & & & \\
\hline PLDTF & 10 & $x$ & $x$ & $x$ & $x$ & $x$ & \\
\hline PSFI & 11 & $x$ & & $x$ & $x$ & & \\
\hline RFMF & 12 & $x$ & $x$ & $x$ & $x$ & $x$ & $x$ \\
\hline SMF & 13 & $x$ & $x$ & $x$ & $x$ & $x$ & $x$ \\
\hline $\mathrm{SF}$ & 14 & & $x$ & $x$ & $x$ & $x$ & $x$ \\
\hline
\end{tabular}

Note: The firms with $\mathrm{x}$ mark represent the efficiency with Increasing Returns to Scale (IRS) in a given year.

Table 8: Number of Firms with Input-Orientated DRS Efficiency

\begin{tabular}{|c|c|c|c|c|c|c|c|}
\hline Firm & No. & 2000 & 2001 & 2002 & 2003 & 2004 & 2005 \\
\hline ASF & 1 & & & & & & \\
\hline AYF & 2 & & & & & $x$ & \\
\hline AFI & 3 & & $x$ & & & $x$ & \\
\hline BBFI & 4 & & & & & & \\
\hline CCFPI & 5 & & & & & & \\
\hline EZF & 6 & & & & & & \\
\hline $\mathrm{MBF}$ & 7 & & & & $x$ & & \\
\hline PALF & 8 & & & & & & \\
\hline PBSP & 9 & & & & & & \\
\hline PLDTF & 10 & & & & & & \\
\hline PSFI & 11 & & & & & & \\
\hline RFMF & 12 & & & & & & \\
\hline SMF & 13 & & & & & & \\
\hline SF & 14 & & & & & & \\
\hline TYKF & 15 & & & & & & \\
\hline
\end{tabular}

Note: The firms with x mark represent the efficiency with Decreasing Returns to Scale (DRS) in a given year.

The most important observation of this result is that over the six-year period, social foundations are mostly operating under CRS and IRS. On average, $65.55 \%$ of social foundations were operating at IRS, $4.45 \%$ at DRS and $30 \%$ at CRS. These findings are aligned with the study of Dacosta-Claro and Lapierre (2003) where CRS and VRS are important considerations in assessing the efficient frontier while using multiple inputs and multiple outputs.

As discussed by Lynch \& Ozcan (1994), an important feature of DEA is the ability to identify slack within individual organizations. Slack describes the magnitude of inefficiency and outlines the overuse of inputs or the underproduction of output (Harrison, 2005). Slack values are obtained by evaluating the levels of inputs in relation to output and provide guidance on improvements needed to make the organization more efficient. Slack analysis measures how much inefficiency can be reduced by reallocation of inputs.

A firm is only technically efficient if it operates on the frontier, and furthermore, that all associated slacks are equal to zero. Thus, zero slacks means that the social foundations are utilizing their input resources efficiently. Moreover, Bowlin (1998) mentioned the non-discretionary variables that have values determined by forces exogenous to the organization under evaluation. Alternatively put, the values of these inputs or outputs are beyond the control of the organization's management. However, in many cases, it is important to take these nondiscretionary inputs into account in an evaluation of a firm's performance. The non-discretionary input used in this paper is "age" or years of existence of the foundation. 
Tables 9 and 11 show the firms that need to reduce their usage of input and output variables as to avoid input excess and output deterioration. Meanwhile, Tables 10 and 12 present the average summary of efficient input and output target. From an input perspective, the results show that the Philippine Social Foundations are characterized by inefficiencies in the management of fixed assets, having an average slack of $14.84 \%$ capital surplus. This finding suggests that social foundations, on average, could have reduced their level of capitalization without any corresponding reduction in their output variables. The other input factors like administrative and operating expenses and number of employees do not suffer the same level of inefficiencies, ranging only from 7.9 to $8.71 \%$.

Table 9: Percentage Summary of Input Slacks (\%), 2000-2005

\begin{tabular}{llccc}
\hline DMU & Foundation & $\begin{array}{c}\text { Admin \& General } \\
\text { Operating Expenses }\end{array}$ & Fixed Assets & Number of Employees \\
\hline 1 & A. Soriano Foundation & 0 & 0 & 36.80 \\
2 & AY Foundation & 8.8 .84 & 0 & 0.42 \\
3 & Ayala foundation & 0 & 21.25 & 0 \\
4 & Bato-Balani Foundation & 10.80 & 8.95 & 9.60 \\
5 & Coca-cola Foundation & 15.43 & 0 & 5.49 \\
6 & E. Zobel Foundation & 0 & 90.10 & 0 \\
7 & Metrobank Foundation & 46.88 & 0 & 0 \\
8 & Phil. Airline Foundation & 0 & 22.05 & 16.16 \\
9 & Phil. Business for Social Progress & 0 & 0.51 & 3.00 \\
10 & Phil. Long Distance Foundation & 17.81 & 7.47 & 0 \\
11 & Pilipinas Shell Foundation & 1.92 & 0 & 9.00 \\
12 & RFM Foundation & 0 & 0.80 & 49.71 \\
13 & SM Foundation & 0 & 49.37 & 0 \\
14 & Splash Foundation & 9.86 & 5.67 & 0.44 \\
15 & Tan Yan Kee Foundation & 6.93 & 16.40 & 0 \\
\hline
\end{tabular}

Table 10: Average Summary of Efficient Input Target, 2000-2005 (Actual Values in Thousand Philippine Pesos)

\begin{tabular}{|c|c|c|c|c|}
\hline DMU & Foundation & $\begin{array}{c}\text { Admin \& General } \\
\text { Operating Expenses }\end{array}$ & Fixed Assets & Number of Employees \\
\hline 1 & A. Soriano Foundation & 0 & 0 & 3.58 \\
\hline 2 & AY Foundation & $1,619.75$ & 0 & 1.14 \\
\hline 3 & Ayala foundation & 0 & $23,797.80$ & 0 \\
\hline 4 & Bato-Balani Foundation & 421.50 & 5.90 & 0.71 \\
\hline 5 & Coca-cola Foundation & $2,000.06$ & 0 & 0.67 \\
\hline 6 & E. Zobel Foundation & 0 & $3,082.05$ & 0 \\
\hline 7 & Metrobank Foundation & $5,157.75$ & 0 & 0 \\
\hline 8 & Phil. Airline Foundation & 0 & 17.12 & 1.01 \\
\hline 9 & Phil. Business for Social Progress & 0 & $5,684.38$ & 56.27 \\
\hline 10 & Phil. Long Distance Foundation & $1,252.08$ & 568.36 & 0 \\
\hline 11 & Pilipinas Shell Foundation & $3,937.27$ & 0 & 10.18 \\
\hline 12 & RFM Foundation & 0 & 41.08 & 1.81 \\
\hline 13 & SM Foundation & 0 & $14,038.49$ & 0 \\
\hline 14 & Splash Foundation & 835.54 & 190.80 & 0.65 \\
\hline 15 & Tan Yan Kee Foundation & $7,346.53$ & $14,014.85$ & 0 \\
\hline
\end{tabular}

For the output slacks, the Philippine social foundations are characterized by a high level of output deterioration, with respect to donations, with an average slack of $3,162 \%$ deterioration. The implication to management is that they need to generate more funds to finance their projects and programs. Interest income and grants/awards to beneficiaries show $890.20 \%$ and $204.58 \%$ deterioration, respectively. Table 12 shows that CocaCola, E. Zobel and Metrobank Foundation failed to meet the target on average real value as far as output donation is concerned. 
Table 11: Percentage Summary of Output Slacks (\%), 2000-2005

\begin{tabular}{llccc}
\hline DMU & Foundation & Donations & Interest Income & Grants \\
\hline 1 & A. Soriano Foundation & $1,066.36$ & 2.81 & 87.48 \\
2 & AY Foundation & 53.50 & 67.02 & 48.81 \\
3 & Ayala foundation & 0.12 & 0 & 39.88 \\
4 & Bato-Balani Foundation & 11.37 & 369.97 & 24.99 \\
5 & Coca-cola Foundation & $9,168.13$ & 0 & 229.76 \\
6 & E. Zobel Foundation & $2,041.17$ & 373.21 & 781.99 \\
7 & Metrobank Foundation & $26,973.07$ & 0 & 20.88 \\
8 & Phil. Airline Foundation & 349.02 & 108.94 & 802.11 \\
9 & Phil. Business For Social Progress & 21.09 & 3.01 & 14.28 \\
10 & Phil. Long Distance Foundation & $1,061.85$ & 112.99 & 163.38 \\
11 & Pilipinas Shell Foundation & $1,203.53$ & 78.78 & 18.94 \\
12 & RFM Foundation & $5,177.05$ & $11,805.81$ & 453.16 \\
13 & SM Foundation & 176.70 & 423.64 & 208.02 \\
14 & Splash Foundation & 58.07 & 6.87 & 134.96 \\
15 & Tan Yan Kee Foundation & 67.72 & 0 & 40.00 \\
\hline
\end{tabular}

Table 12: Average Summary of Efficient Output Target, 2000-2005 (Actual Values in Thousand Philippine Pesos)

\begin{tabular}{llccc}
\hline DMU & Foundation & Donations & Interest Income & Grants \\
\hline 1 & A. Soriano Foundation & $8,612.92$ & 70.10 & $9,577.79$ \\
2 & AY Foundation & $22,934.97$ & 267.02 & $22,272.58$ \\
3 & Ayala foundation & 0 & 0 & $90,313.01$ \\
4 & Bato-Balani Foundation & $10,590.26$ & 98.22 & $1,0673.70$ \\
5 & Coca-cola Foundation & $11,654.46$ & 0 & $20,412.25$ \\
6 & E. Zobel Foundation & $37,308.93$ & 485.68 & $37,945.63$ \\
7 & Metrobank Foundation & $43,063.21$ & 0 & $52,605.69$ \\
8 & Phil. Airline Foundation & $12,414.38$ & 64.97 & $12,274.24$ \\
9 & Phil. Business For Social Progress & $1,4619.20$ & $13,767.48$ & $72,303.06$ \\
10 & Phil. Long Distance Foundation & $16,735.33$ & 43.00 & $13,546.54$ \\
11 & Pilipinas Shell Foundation & $34,444.65$ & 964.64 & $36,519.44$ \\
12 & RFM Foundation & $16,009.26$ & 253.39 & $16,357.38$ \\
13 & SM Foundation & $80,922.46$ & $1,024.22$ & $58,241.43$ \\
14 & Splash Foundation & $13,044.51$ & 171.15 & $1,4387.40$ \\
15 & Tan Yan Kee Foundation & $4,6512.50$ & 0 & $23,395.43$ \\
\hline
\end{tabular}

By combining input-output slack analysis, there exists a clear managerial implication for strategy: To reduce the capitalization and to convert such reduction into cash for donations. This can be called a case of "asset to cash conversion". It is worthy to note that for a social foundation, liquidity factor is of prime importance since it always needs cash to finance its projects. This is another justification for the use of DEA. Without DEA, it would have been difficult to come up with this kind of management strategy.

\section{CONCLUSIONS}

The DEA method is used to analyze the relative efficiency of the Philippine social foundations and benchmark each other's performance. Newly derived findings imply that social foundations are fairly inefficient based on selected DEA variables only. It must be kept in mind that an individual foundation's vision, mission, goals and objectives are not taken as part of the criteria for this current efficiency analysis.

Without DEA, it would have been very difficult to assign an efficiency factor to these social foundations because of multiple inputs and outputs that need to be analyzed beyond the profit measurement, as an indicator of performance. With the aid of a DEA tool, the efficiency measurement and assessment of social foundations has become manageable and quantifiable from a multidimensional context. This is a significant added new contribution to efficiency assessment of the non-profit sector. The findings have also organizational implications; i.e., the 
management of foundations should be able to evaluate their own performance relative to other foundations using other non-financial indicators. These corporate foundations must find ways to function efficiently by looking at other sources of funds to support existing and future projects. The identification of efficient foundations can allow management to emulate to improve their own efficiency performance. New findings (slack analysis) in this paper may lead management to extend better and efficient allocation of grants to their beneficiaries.

This research has shown the importance of the application of DEA to a non-profit sector, such as social foundations, when the measurement of performance becomes problematic and be taken as beyond the profit area of performance analysis. In our small sample size, as well as the multidimensional characteristic of social foundations, a deterministic DEA is a more suitable tool for performance evaluation and benchmarking purposes. This also forms as an inevitable limitation of this current research. For future research, an increase of sample size and the effects of other non-discretionary factors to organizational performance may be subject for a broader critical analysis by using other non-frontier or frontier approaches that are currently beyond the scope of this paper.

\section{AUTHOR INFORMATION}

Imelda S. Dorado is accounting staff at the University of Santo Tomas in the Philippines. She holds a Master's degree in Business Administration from the same university. Her research interests include non-profit organization, performance, and efficiency analysis.

Emilyn Cabanda is Associate Professor in the School of Global Leadership and Entrepreneurship at Regent University, Virginia Beach. Dr. Cabanda has also taught at the University of Santo Tomas, Philippines and held visiting positions at Yokohama National University and International Christian University in Japan. Her latest book is Privatisation and Performance of Asian Telecommunications (2010). Her research interests include performance management, operations research, efficiency and productivity, and global business.

\section{ACKNOWLEDGEMENT}

This study was conducted with the financial support from Graduate School, Accounting and the Grants Office of the University of Santo Tomas, Manila Philippines for the travel grant extended for the presentation of this paper at the EURO XXII, held in Czech Republic on July 8-11, 2007.

\section{REFERENCES}

1. Abbot, M., Doucouliagos, C., (2003). The Efficiency of Australian Universities: A DEA. Economics of Education Review 22, 89-97.

2. Ahn, T., Charnes, A., Cooper, W.W., (1988). Using Data Envelopment Analysis to Measure the Efficiency of Non-profit Organizations: a Critical Evaluation-Comment. Managerial and Decision Economics (19861988): 9(3), 251-253.

3. Athanassopoulos, A., Shale, E., (1997). Assessing the Comparative Efficiency of Higher Education Institutions in the UK by Means of Data Envelopment Analysis". Education Economics 5(2), 117-134.

4. Bougnol, M., Dula, J., (2006). Validating DEA as a ranking tool: An application of DEA to assess performance in higher education. Annals of Operations Research 145, $339-365$.

5. Bowlin, W.,(1998). Measuring Performance: An Introduction to Data Envelopment Analysis (DEA), Journal of Cost Analysis 3(3), 3-27.

6. Biorn, E., Hagen, TP, Iversen, T., Magnussen, J., (2003). The Effect of Activity Based on Hospital Efficiency: A Panel Data Analysis of Data Envelopment Analysis scores 1992 - 2004. Health Care Management Science 6(4), 271-83.

7. Castelli, L, Pesenti, R., Ukovich, W., (2003). DEA like models for the efficiency evaluation of hierarchically structured units. European Journal of Operational Research 154, 465-476.

8. Castano, M.C., Cabanda, E., (2007). Performance of Philippine Higher Educational Institutions: Application of Frontier Approaches. International Transaction in Operational Research (ITOR) 14, 431444. 
9. Coelli, T., Rao, DS, O’Donnell, C., Battese, G., (2005). “An Introduction to Efficiency and Productivity Analysis $2^{\text {nd }}$ Edition". New York: Springer Science+Business Media, Inc.

10. Cook, Wade and Zhu, Zoe (2005). Modeling Performance Measurement: Applications and Implementations Issues in DEA. New York: Springer.

11. Charnes, A. Cooper, W, Rhodes, E., (1978). Measuring the Efficiency of Decision-Making Unit. European Journal of Operational Research 2, 429-444.

12. Dacosta-Claro, I., Sophie, L., (2003). Benchmarking as a tool for the improvement of health services' supply departments. Health Services Management Research 16, 211-223.

13. Farell, M.J., (1957). The Measurement of Productive Efficiency. J. R. Stat. Soc., Ser A, III, 120, 253-281.

14. Joumady, O., Ris, C.,(2005). Performance in European Higher Education: A Non-Parametric Production Frontier Approach. Education Economics 13(2), 189-205.

15. Lynch, J., Ozcan, Y., (1994). Hospital closure: An efficiency analysis. Hospital \& Health Services Administration 39(2), 205-220.

16. Martin, E.,(2006). Efficiency and Quality in the Current Higher Education context in Europe: an application of the data envelopment analysis methodology to performance assessment of departments within the University of Zaragosa. Quality in Higher Education 12(1), 57-79

17. Ng, Y.C., Li, S.K., (2000). Measuring the Research Performance of Chinese Higher Education Institutions: An application of DEA". Education Economies 8(2), 139-156.

18. Nunamaker, T.,(1985). Using Data Envelopment Analysis to Measure the Efficiency of Non-profit Organizations: a Critical Evaluation”. Managerial and Decision Economics 6(1), 50-58.

19. Nunamaker, T.,(1989). Using Data Envelopment Analysis to Measure the Efficiency of Non-profit Organizations: a Critical Evaluation-Reply. Managerial and Decision Economics 9(3), 255-256.

20. Nyhan, R., Cruise, P., (2000). Comparative Performance Assessment in Managed Care: Date Envelopment Analysis for Health Care Manager. Managed Care Quarterly 1, 18-27.

21. Ramanathan, R.,(2003). An Introduction to Data Envelopment Analysis: A Tool for Performance Measurement. New Delhi: Sage Publications.

22. Robst, J., (2001). Cost Efficiency in Public Higher Education Institution. Journal of Higher Education 72 (6), 730-750.

23. Taylor, B., Harris, G., (2004). Relative Efficiency among South African universities: A Data Envelopment. Higher Education 47, 73-89.

24. Thompson, RG., Dharmapala, PS, Gatewood, EJ, Macy, S.,(1996). DEA/Assurance Region SBDC Efficiency and Unique Projections. Operations Research 44 (4), 533-542. 
NOTES 